\section{Prof. Yoav Bashan}

\section{October 12 1951-September 192018}

Published online: 16 January 2019

(C) Springer-Verlag GmbH Germany, part of Springer Nature 2019

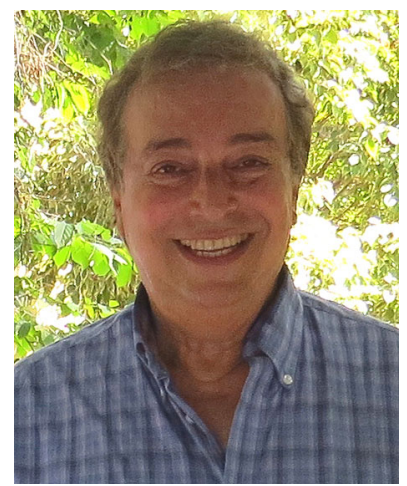

Yoav Bashan was born in Haifa, Israel. He received his doctoral degree from the Hebrew University of Jerusalem, and had postdoctoral stays at the Weissman Institute in Israel and at Ohio State University. The majority of his academic life was linked to Mexico. In 1990 he relocated to La Paz, Baja California Sur, to take the position of Head of the Microbiology Department at the Center for Biological Research of the Northwest (CIBNOR). Since 1997 he was the Leader of the Environmental Microbiology Group at CIBNOR. He was also President of the Bashan Foundation, an international institute dedicated to the dissemination of scientific information, and the President of the Bashan Institute of Science, a newly formed organization dedicated to environmental research, located in Auburn, Alabama. Yoav was also an Affiliated Full Professor with the Department of Entomology and Plant Pathology at Auburn University. For more than three decades his research areas were environmental microbiology, plant-bacteria interaction in aquatic and terrestrial environments, ecological restoration of disturbed environments and water bioremediation. Yoav was a leading figure in the Plant Growth-Promoting Bacteria (PGPB) field, extending their use from agriculture to environmental applications. Yoav published over 350 scientific papers, 80 book chapters and acted as advisor to more than 40 graduate students.

Although it is clear that the scientific contributions of Yoav were outstanding, without a doubt those who knew him would say that his humanity and sense of humor equaled his academic achievements. He was a generous and patient teacher, openminded and a freethinker. Yoav was always making new acquaintances and keeping in touch with old friends. He had a broad interest in art and culture, with many hobbies outside of the scientific world. He was an outstanding cook, painter, photographer and traveler; in short, he enjoyed all things in life.

Luz de-Bashan

Environmental Microbiology Group, CIBNOR, Mexico

Bashan Institute of Science, USA

The Bashan Foundation, USA

Publisher's note Springer Nature remains neutral with regard to jurisdictional claims in published maps and institutional affiliations. 